\title{
Parent Relationship Satisfaction and Reflective Functioning as Predictors of Emotional Availability and Infant Behavior
}

\author{
Saara J. Salo ${ }^{1}{ }^{1} \cdot$ Marjukka Pajulo $^{1,2} \cdot$ Lazlo Vinzce $^{1} \cdot$ Simo Raittila $^{1} \cdot$ Johanna Sourander $^{1} \cdot$ Mirjam Kalland $^{1}$
}

Received: 9 December 2019 / Accepted: 20 February 2021 / Published online: 12 March 2021

(c) The Author(s) 2021

\begin{abstract}
Marital and parenting systems are likely to interact during the first year of an infant's life. This study examines the longitudinal interrelations of relationship satisfaction and parental reflective functioning (PRF) and their predictive relations with later emotional availability (EA) and infant social-emotional behaviors (SEB) including skills as well as behavioral problems among first-time Finnish mothers and fathers $(\mathrm{n}=556)$. The follow-up period was between three and 12 months. In addition to having direct effects, we examined a mediational model in which self-reports on PRF factors of interest and curiosity and appropriateness of reasoning would mediate the effects of previous relationship satisfaction to the parent and dyadic side of EA and infant SEB at 12 months. The results show significant stability for relationship satisfaction and PRF for both mothers and fathers as well as direct effects on EA and SEB. However, we found differences between mothers and fathers. For mothers, path analysis indicated support for a mediational model where earlier relationship satisfaction predicted later EA and infant problem behaviors also through the current level of PRF. For fathers, both relationship satisfaction and PRF had direct, but not mediated, effects, and on both infant problem behaviors as well as infant social competence. Together, despite these differences, focusing clinically on both relationship satisfaction and PRF may prove significant in preventing later relational and/or infant difficulties in SEB for both mothers and fathers.
\end{abstract}

Keywords Relationship satisfaction $\cdot$ Parental reflective functioning $\cdot$ Emotional availability $\cdot$ Infant social-emotional behavior

\section{Highlights}

- Relationship satisfaction and parental reflective functioning are stable across the first year of infant's life.

- Relationship satisfaction and parental reflective functioning predict emotional availability and infant social-emotional behavior.

- For mothers, there may be a spillover effect of earlier relationship satisfaction predicting higher level.

- of parental reflective functioning, which, in turn is related to higher emotional availability and less perceived infant problem behaviors.

- Early preventive work should focus on both relationship satisfaction as well as improving parental reflective functioning among first-time parents.

The first year in parenthood can be both incredibly gratifying and as well as stressful for new parents (Cowan and Cowan 2012; Holmes et al. 2013). In line with the family

\footnotetext{
Saara J. Salo

saara.z.salo@helsinki.fi

Helsinki University, Helsinki, Finland

2 Turku University, Turku, Finland
}

systems theory, couple relational and parenting subsystems may interact and relationship problems may spillover into the developing parenting skills (Christopher et al. 2015) affecting the child's development (Knopp et al. 2017) and the developing parent-child relationship (Kouros et al. 2014). Parental reflective functioning (PRF) helps (new) parents to take their child's perspective and understand their behavior (Slade 2005; Camoirano 2017) and has recently been underlined as helping parents to navigate the transition to parenthood and their new roles. However, to date little is 
empirically known about the interrelationship between relationship satisfaction, PRF and infant social-emotional behavior (SEB) among parents with their first-born children during infancy. Clinically, understanding how relationship satisfaction and PRF are interrelated may also help develop early interventions for couples at risk for later relational or infant developmental negative outcomes.

Research has systematically shown declines in the relationship satisfaction during the transition to parenthood (Don and Mickelson 2014; Doss and Rhoades 2017; Lawrence et al. 2008). Parents of infants, especially mothers, seem to have the lowest satisfaction (Twenge et al. 2003) compared to nonparents with similar lengths of relationships (Lawrence et al. 2008). The increase in dissatisfaction involves both a decline in the positive aspects of the relationship such as affection and intimacy, and a rise in the negative, such as conflicts lasting long beyond the infancy period (Doss et al. 2009), as well as changes in overall family dynamics (Lindblom et al. 2017). However, in recent years, research has moved beyond assessing the mere trajectories of stability and change and focused instead on uncovering related factors that could interact with relationship satisfaction in protective or vulnerating ways when predicting later developmental outcomes.

One closely related parental mechanism could be the skill or capability called parental reflective functioning (PRF) meaning the parental capacity to show coherent and appropriate appreciation of the infant's internal states. New parents must learn how to interact with their babies and for that they need a new understanding of their baby's unique personality and their own new roles as parents. Reflective functioning (RF) is a measure of mentalizing - the capacity to think about one's own and others' thoughts and feelings and understand the connections between mental states and behaviors (Fonagy et al. 2002). PRF refers to a parent's specific skill of understanding the separateness between their own and their child's minds, and understanding that the child's behaviors are a result of underlying emotional states, goals, and intentions (Slade 2005). Parents are thus able to be open, curious and interested and make accurate interpretations about their child's internal experiences rather than simply responding to his or her observable behaviors. PRF is typically measured from either an interview or a questionnaire about the parent's relationship with their child (Luyten et al. 2017; Slade et al. 2005; Pajulo et al. 2018). Parents who are characterized as having a low PRF seem unaware of their own or their child's thoughts or feelings and deny emotional experiences associated with parenting. On the other hand, highly reflective parents are aware and curious about their own and others' emotions, understand how their mental states impact their own and others' behavior, and understand the complexities of mental states (Slade et al. 2005). PRF starts to develop prenatally when parents are preparing for future parenthood in their minds (Slade et al. 2009). However, there have been few studies examining the stability of PRF during infancy. In Wong's (2016) study, PRF showed stability from pregnancy until seven months of age among non-risk parents, while other studies have mainly focused on clinical samples and examined changes in PRF after various early interventions (Pajulo et al. 2012; Salo et al. 2019; Suchman et al. 2017).

Relationship dissatisfaction is likely to be related to PRF in that the more stress and negative emotions the parent experiences in their current close relations, the more difficult it may be to focus on understanding the child's emotions and related behaviors. Heightened arousal is generally thought to underlie the switch from mentalizing to nonmentalizing modes, indicative of low RF (Luyten and Fonagy 2015). Indeed, Luyten et al. (2017) found an association between low quality of marital relationship and a questionnaire measuring parental reflective functioning, PRFQ (Parent Reflective Functioning Questionnaire), especially regarding a dimension measuring pre-mentalizing states indicative of low RF. Parents who have mentalizing difficulties have also reported generally lower satisfaction in their parental role (Rostad and Whitaker 2016). Alternatively, from a systemic perspective, a parent with high general RF (not just related to parenting) may have more skills in parental reflectiveness too, and, furthermore, be more likely to reflect and understand their spouse thus increasing the potential for relationship satisfaction. Indeed, a recent study by Jessee et al. (2018) showed that higher RF measured prenatally was related to more positive marital quality later as well as good co-parenting quality in infancy among mothers. Interestingly, in comparison, fathers' RF was not significantly associated with marital satisfaction or co-parenting quality. However, this study did not specifically focus on PRF, as the assessment of reflectiveness was made on the basis of an adult attachment interview (AAI$\mathrm{RF}$ ), which focuses on the insightfulness and understanding of the parent's own parental attachment history. Although conceptually related, PRF and RF measured from the AAI focus on reflectiveness related to different relationships, one's own parents vs. the child (Luyten et al. 2017; Steele et al. 2008), and PRF may only fully develop once the child is born. Furthermore, previous studies have not followed the developmental stability or change of PRF and relationship satisfaction together during the infancy period.

Importantly, while the parents undergo a transition in their couple relationship and developing reflective skills, the infant is completely dependent on the parents' daily emotional caregiving. In line with the family systems theoretical spillover hypothesis, both relationship satisfaction and PRF may act either as protective or risk factors in terms of the development of this emotional relationship and as well as the child's early social-emotional development. Consistent 
with these predictions, low relationship satisfaction has been shown to be a risk factor for later parent-child relationship problems (Kouros et al. 2014), and child wellbeing (Heinrichs et al. 2010) even long beyond the infancy period (Lindblom et al. 2017). For example, Knopp et al. (2017) showed that parents of children who reported lower levels of relationship satisfaction also reported more behavioral problems in the child. However, results regarding the relations have also differed between mothers and fathers. Panula et al. (2020) showed that mother's relationship dissatisfaction significantly predicted lower perceived social competence in the child at 3 years of age. Furthermore, mother's prenatal higher relationship satisfaction was systematically associated with a better family relationship while the father's experience of relationship satisfaction was not related to a better family relationship during infancy (Korja et al. 2016). In contrast, Christopher et al. (2015) demonstrated that declines in fathers' relationship satisfaction from prenatal to 24 months predicted lower involvement by the father, e.g., less involvement in making parental decisions or performing parenting tasks. Together these previous results underline the importance of studying mothers and father separately.

PRF has also been systematically linked to more optimal parent-child relational qualities as well as a lower level of behavioral problems and higher levels of social skills in the child (for a review, see Camoirano 2017). Specifically, a previous cross-sectional study examining the relations between PRFQ and a relational construct called the emotional availability (EA; Biringen et al. 2014) found that higher PRFQ ratings at the age of 12 months were associated with higher parental selfratings of their EA dimensions (Luyten et al. 2017). Similarly, Rostad and Whitaker (2016) found that parental interest and curiosity in mental states as assessed by the PRFQ were associated with the degree of satisfaction with parenting involvement, and communication, while Rutherford et al. (2013) found that PRFQ was related to the mother's tolerance of infant distress. Finally, using an interview-based measurement of PRF (PDI-RF; Slade et al. 2005) and observational method for assessing EA (Biringen 2008) in an intervention study by Salo et al. (2019) likewise found that maternal RF was related to EA at the age of 12 months. However, none of the previous studies tested simultaneously the joint effects of the relationship satisfaction and PRF on EA and infant SEB, including both positive social-emotional skills as well as behavioral problems, during infancy and most of them involved only assessing mothers.

There may also be several contextual factors that need to be taken into account when examining the associations between relationship satisfaction, PRF and later child outcomes. Prospective data have recently shown that when compared to married woman, cohabiting women experience more relationship dissatisfaction and they stayed less satisfied throughout the transition period into parenthood (Mortensen et al. 2012). Likewise, in terms of the PRF, a number of contextual factors have already been shown to be related to the capacity for the developing PRF, including low SES (Rosenblum et al. 2008), and whether the pregnancy was planned or not (Pajulo et al. 2006).

Finally, over the past decades, the parenting literature has contained frequent calls for the systematic inclusion of both mothers and fathers. Indeed, the few parenting studies that use reports from both fathers and mothers regarding relationship satisfaction and/or relationship discord have used either total or average scores of relationship satisfaction of both spouses (Sturge-Apple et al. 2004) or use the summed scores as manifest indicators to create a single latent construct (Kaczynski et al. 2006). In addition, many parenting studies assess relationship satisfaction according to one reporter (Davies et al. 2009), despite the findings that there might be gender-related differences in relationship satisfaction (Lawrence et al. 2008) and hence how it is related to parent-child interaction (Korja et al. 2016) as well as reflective functioning (Jessee et al. 2018). Also, the previous PRF literature has generally mainly focused on mothers (Camoirano 2017).

Our main research question was to study how relationship satisfaction and PRF measured at three and 12 months predicted EA and infant SEB at 12 months and whether there were differences between the mothers and fathers. First, we hypothesized that even after controlling for confounding variables of SES, relationship status, and whether the pregnancy was planned for, relationship satisfaction and PRF would be highly stable from three to 12 months. Second, we hypothesized direct effects in that higher relationship satisfaction and PRF would predict higher EA, lower infant behavioral problems and higher social competence at 12 months. Thirdly, we hypothesized that the results support the spillover model, in which relationship satisfaction at the age of three months would predict higher PRF at 12 months, which in turn, would predict higher EA and lower behavioral problems and higher social competence. However, as there has been little empirical study on the longitudinal interrelations between relationship satisfaction and PRF, crossover effects would be indicated by the presence of indirect effects from relationship satisfaction at three months to EA and infant behavioral problems and social competence at 12 months mediated by PRF. We therefore regarded these tests as exploratory. Finally, given that there has been so little research comparing mothers and fathers PRF, no hypotheses were set regarding the differences in the associations between the study variables. 


\section{Method}

\section{Participants and Procedure}

The study sample was a community-based sample of pregnant first-time parents from 80 communities all over Finland, who were invited to take part in the study within the system of maternity and well-baby clinics between $1 /$ 2014 and 10/2015 (Kalland et al. 2016). The current study is part of a larger study on first-time parents in Finland, called the Families First -study. The study follows 1016 first-time parents-to-be from pregnancy until the child is around two years old at five separate study points, with an option for later follow-ups. The scientific goal of the study is to study the well-being of children and their parents and to study how the development to become a parent (mother or father) in Finland today is affected by previous experiences in childhood, by relationship status and quality and by informal and formal social support. For the current study, we investigated the three- and 12-month study points. The ethical committee of the Finnish National Institute approved the study plan for Health and Wellbeing.

In Finland, all pregnant mothers and their partners are provided cost-free services during pregnancy in maternity clinics within primary health care. Similarly, when the baby is born, the family is provided with cost-free primary health care services and health check-ups for the infant in the wellbaby clinics until the child is seven years old. The service includes two home-visits, one at week 30-32 of pregnancy and the other 1-7 days after returning home after the delivery. According to national statistics, $99.7 \%$ of the mothers use the service during pregnancy. Of high-risk mothers, as many as $97.8 \%$ use the services. (Kalland et al. 2006). All first-time parents, both mothers and fathers, are also offered the possibility to take part in cost-free antenatal classes (Hakulinen-Viitanen and Pelkonen 2009), and most of them do. The services at the well-baby clinics are free of charge for the families and the dropout rate is less than $1 \%$.

The data collection was carried out using questionnaires provided on the Internet and available through a personal code. Paper versions of the questionnaires were also available upon request. The public health nurses in the maternity clinics informed potential participants (parents expecting their first child) about the study at a regular visit during the third trimester of pregnancy. The average gestational week the mothers answered the first survey was 34.4 (SD 3.2). The nurses were specifically instructed not to pick certain families for the study, but to provide the opportunity to all first-time parents during a regular check-up. Either mother or father or both received written information regarding the study as well as forms for informed consent together with a prepaid envelope. Mothers and fathers in the study filled in the same questionnaires separately from each other.
Table 1 Participants' socio demographic characteristics at baseline (three months)

\begin{tabular}{llllll}
\hline Baseline characteristics & \multicolumn{2}{l}{ Mothers } & & \multicolumn{2}{l}{ Fathers } \\
\cline { 2 - 3 } \cline { 5 - 6 } & $M$ & & & $M$ & $S D$ \\
\hline Age & 29.47 & 4.54 & & 31.5 & 4.66 \\
& $n$ & $\%$ & & $n$ & $\%$ \\
Level of education & & & & \\
Basic education & 10 & 2.3 & & 5.5 \\
Vocational 2nd degree & 103 & 24 & & 37 & 29.1 \\
Vocational 3rd degree & 161 & 37.5 & 39 & 30.7 \\
Academic & 155 & 36.1 & 44 & 34.6 \\
Marital status & & & & \\
Married & 231 & 53.8 & 86 & 67.7 \\
Cohabiting & 187 & 43.6 & 39 & 30.7 \\
Single & 11 & 2.6 & 2 & 1.6 \\
Planned pregnancy & & & & \\
Yes & 374 & 91.4 & 118 & 97.5 \\
No & 35 & 8.6 & 3 & 2.5 \\
\hline
\end{tabular}

$N$ varies between $409-429$ for mothers and 121-127 for fathers due to missing data

All parents gave their voluntary, informed consent for treatment and were informed of their rights to leave the study or treatment at any time.

\section{Measures}

\section{Sociodemographic characteristics of the sample}

The background information used in the present study included parental age, marital status, and parental level of education. We also asked if the baby had been planned for or not. The level of education was used to assess SES because it captures the transition from own parents' (received) socioeconomic position to adulthood (own) (Galobardes et al. 2006), and predicts various health outcomes and well-being (Sheikh et al. 2017). The four categories of education presented in Table 1 represent the following: 1) basic level = compulsory school of 9 years, 2) vocational $2^{\text {nd }}$ degree $=$ professional training, high school 3) vocational $3^{\text {rd }}$ degree $=$ polytechnic degree, 4) high $=$ academic (basic or research degree). In the analyses a dichotomous variable for educational level high (polytechnic and academic degree) and educational level low (compulsory school and professional/high school) was used instead of all four categories. The most largest and meaningful differences in terms of various health and well-being outcomes have previously been found only between the highest and lowest educational categories in Finland (Talala et al. 2014). In Finland, the differences between the mid-categories may not show meaningful differences because they are fairly close to each other in terms of the quality of the education and the equal 
possibilities of people obtaining them (due to free university and second grade education in Finland).

\section{Index of Marital Satisfaction}

For assessing the relationship satisfaction, we used the Index of Marital Satisfaction (IMS) (Hudson 1997). The IMS is a 25-item scale designed to measure the degree of satisfaction people have with their relationship. The item scores range from 1-7, theoretical range hence 25-175. A higher score indicates more dissatisfaction being experienced in the relationship. The IMS has been found to have good internal consistency $(\alpha=0.96)$, concurrent, construct and discrimination validity (Hudson 1997). The cut-off score, indicating problems in the relationship, is 25 for men and 28 for women. A score of 70 or over indicates serious problems in the relationship. In this study, estimates of internal consistency were $\alpha=0.95$ for mothers and $\alpha=$ 0.96 for fathers at three months, and $\alpha=0.97$ for both at 12 months.

\section{Parental Reflective Functioning Questionnaire-Fi}

For assessing the PRF we used the Finnish shortened version of the original Parental Reflective Functioning Questionnaire (PRFQ; Luyten et al. 2017) called the PRFQ-Fi (Pajulo et al. 2018). In the study by Pajulo and colleagues, in a large population-based sample of Finnish infants, exploratory and confirmatory factor analysis resulted in a 14-item version comprising four factors capturing relevant aspects of early parental reflective functioning, namely, (1) interest and curiosity in child's individual mental states (5 items; e.g., "I am often curious to find out how my baby feels"), (2) understanding the opaque nature of mental states (3 items; e.g., "My child can react to a situation very differently than I think he/she will"), (3) appropriateness of reasoning about mental states underlying child's reactions (3 items; e.g., "I hate it when my baby cries and/or seeks my attention just when I am on the phone with someone") and (4) acknowledging the uncertainty in interpreting the child's mental states (3 items; e.g., "I always know why my baby reacts the way he/she does"). Each scale is rated on a 7-point Likert-scale ranging from 1 "strongly disagree") to 7 ("strongly agree"). In the current study, before any statistical analysis, the scores of the answers were converted according to the scoring key in order to have the responses all in same direction (higher score indicating higher mentalization). Estimates of internal consistency (Cronbach's alfa) for interest and curiosity were $\alpha=0.79$ for mothers and $\alpha=0.84$ for fathers at three months, and $\alpha=0.78$ for mothers and $\alpha=0.82$ for fathers at 12 months; for understanding the opaque nature of mental states $\alpha=0.55$ for both at three months, and $\alpha=0.63$ for mothers and $\alpha=0.56$ for fathers at 12 months; for appropriateness of reasoning $\alpha=0.77$ for mothers and $\alpha=0.84$ for fathers at three months, and $\alpha=0.89$ for mothers and $\alpha=0.78$ for fathers at 12 months; for uncertainty about mental states $\alpha=0.60$ for mothers and $\alpha=0.46$ for fathers at three months, and $\alpha=0.43$ for mothers and $\alpha=0.57$ for fathers at 12 months. Given the low level of internal consistencies for two of the PRFQ-Fi scales (understanding the opaque nature of mental states and uncertainty about mental states), only interest and curiosity and appropriateness of reasoning scales have been reported in the present study.

\section{The Emotional Availability-Self Report (EA-SR)}

EA-SR (Vliegen et al. 2009) assesses the emotional availability of the parent, the child, and aspects of dyadic interaction. The EA-SR consists of 36 items pertaining to two parental subscales, namely (1) intrusiveness (six items; e.g., "I find it hard to see my child playing on his own, I prefer to do things together when we're at home") and (2) hostility (comprising two items; e.g., "It happens that I shout at my child to make something clear"), one child subscale, involvement (comprising nine items; e.g., "My child is able to get my attention for his/her play"), and two dyadic subscales (1) mutual Attunement (10 items; e.g., "I succeed in adjusting to my child's behaviors and actions when necessary") and (2) affect quality (five items; e.g., "My child clearly enjoys being with me"). Each scale is rated on a 5-point Likert scale: 0 (disagree completely), 1 (tend to disagree), 2 (neutral), 3 (tend to agree), 4 (agree completely). In this study, we used the single subscales and also calculated a parental emotional availability scale (by reverse coding the intrusiveness and hostility subscales, such that higher scores reflected higher parental emotional availability, and then averaging both scores), a child emotional availability scale (consisting of the involvement subscale), and a dyadic emotional availability scale (by averaging the scores on the mutual attunement and affect quality subscales). Estimates of internal consistency in this study for the parent scale were $\alpha=0.70$ mothers and $\alpha=$ 0.77 fathers; child involvement with parent (child) $\alpha=0.62$ for mothers and $\alpha=0.56$ for fathers, and for the dyadic scale $\alpha=0.82$ for mothers and $\alpha=0.86$ for fathers. Given the low level of internal consistencies for the child involvement with the parent scale, only parent and dyadic EA scales have been reported in the present study.

\section{Brief Infant-Toddler Social and Emotional Assessment (BITSEA)}

The BITSEA-problem scale (BITSEA/P) is comprised of 31 items and the BITSEA-competence scale (BITSEA/C) is comprised of 11 items (Briggs-Gowan et al. 2002). Higher 
Fig. 1 The proposed model of paths between study variables

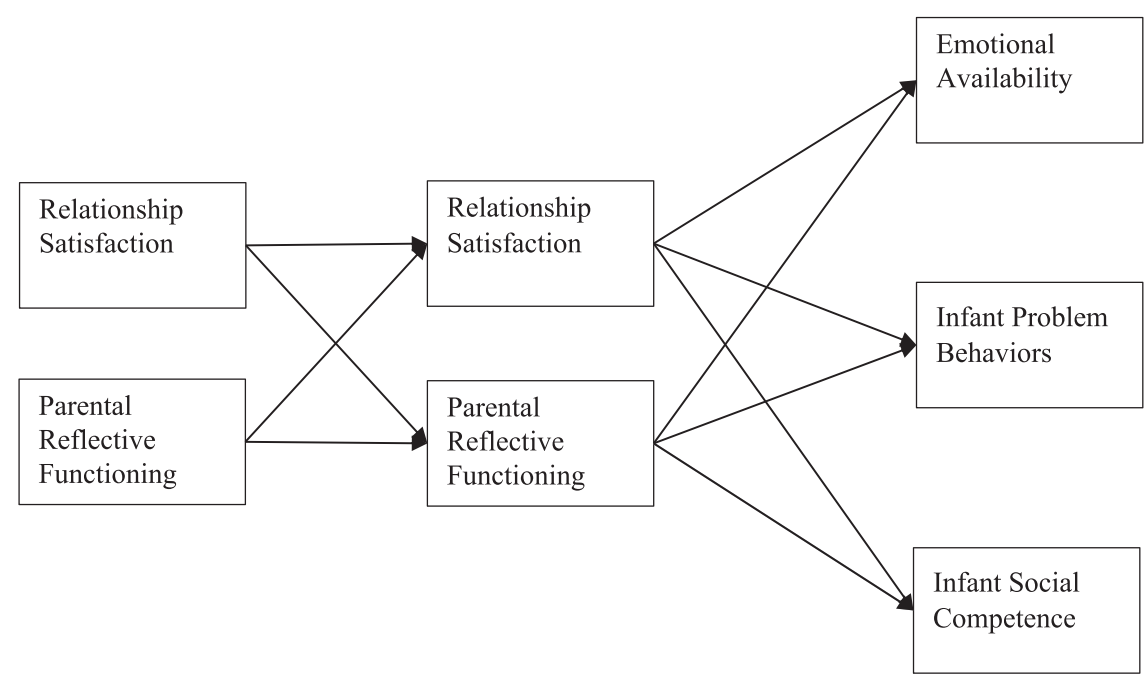

total scores on BITSEA/P indicate a higher level of behavioral and emotional problems and lower total scores on BITSEA/C indicate a lower level of social and emotional competence. The reliability and validity of the BITSEA has been consistently evaluated as good in international studies including those conducted in Finland (Haapsamo et al. 2009). Estimates of internal consistency for the problem scale were $\alpha=0.74$ for mothers and $\alpha=0.81$ for fathers, and for the competence scale $\alpha=0.70$ for mothers and $\alpha=$ 0.77 for fathers.

\section{Data Analysis Strategy}

The preliminary analysis for means, standard deviations and bivariate correlations of the study variables were performed using the SPSS version 25. As preliminary analysis, attrition analysis was first conducted using Student's t-test or chi-square test (depending on whether the variable was continuous or categorical) comparing the baseline (prenatal) and participants who participated in three and 12 month follow-ups in terms of the socio economical background variables (age, marital status, educational level). Second, we compared whether there were differences between mothers and fathers in background variables using Student's t-test or chi-square test (depending whether the variable was continuous or categorical). Descriptive statistics were then conducted to evaluate distribution, mean, and standard deviation $(S D)$ of the study variables, and comparisons were made whether there were differences between mothers and fathers (Student's t-test). To address the study questions, we first conducted bivariate correlations (Pearson's $r$ ) between the study variables. Second, to explore how relationship satisfaction and PRF measured at three and 12 months predicted EA and infant SEB at 12 month, a path analysis was performed with Mplus 8 (Muthén and Muthén 1998-2017). The proposed model is depicted in Fig. 1. Prior to path analysis, we combined interest and curiosity and appropriateness of reasoning subscales scales yielding Parental Reflective Functioning (PRF), while the parent and dyadic EA scales were added together yielding Emotional Availability (EA). Relationship satisfaction and PRF at three months were entered as independent variables, then relationship satisfaction at 12 months and PRF at 12 months as mediators, whereas EA and infant SEB as dependent variables. Indirect effects were calculated by bootstrapping. We also tested a separate model including the covariates for mothers (this model could not be tested for fathers, due to the small sample size). Finally, gender differences were assessed in the pattern and magnitude of relations by performing the analyses separately for mothers and fathers. As the models were considered exploratory (testing all possible causal relations between the independent and mediator variables) and they were thus saturated, fit indices are not available.

\section{Results}

\section{Participant Characteristics}

In the survey three months after delivery, the participants were 708 parents of whom 522 were mothers and 186 were fathers. Participating in both study phases, at three and 12 months, were 429 (82.2\% from the three-month study phase) mothers and 127 fathers (68\% from the three-month study phase). When parents with complete data from both 
time points were compared with parents for whom only either the three-month survey or 12-month survey was missing, there was a significant difference in maternal age, $(t(267)=2.446, p<0.05)$, and in the proportion of mothers who were married rather than cohabiting $\left(\chi^{2}(2)=7.491\right.$, $p<0.05)$, as well as educational attainment $\left(\chi^{2}(3)=11.165\right.$, $p<0.05)$. The mothers with complete data were more likely to be older, married and have a higher level of education. The fathers with complete data and included in the study were more often married $\left(\chi^{2}(1)=9.201, p<0.01\right)$, and had a higher level of education $\left(\chi^{2}(3)=10.608, p<0.05\right)$.

The vast majority of the participants were married or cohabiting (97.6\%), between ages of 18-49 (for mothers $M=29.47, S D=4.54$ and for fathers $M=31.5, S D=4.66$, had more than compulsory school (9 years) education (96.9\%), and their pregnancies were planned for $(92.8 \%)$. Mothers and fathers did not differ in age, $t(540)=-4.35$, ns., educational level, $\chi^{2}(3)=5.592$, ns., marital status, $\chi^{2}$ $(2)=8.20$, ns., or whether the baby was planned for, $\chi^{2}(1)$ $=5.183$, ns.

\section{Preliminary Analyses}

We calculated descriptive statistics (means and standard deviations) regarding mothers' and fathers' relationship satisfaction, PRF, EA and infant SEB at the two assessment points (see Table 2). From the study variables, mothers and fathers differed in interest and curiosity and appropriateness of reasoning at three months, $t(554)=3.29, p<0.05$, $t(554)=3.20, p<0.05$, respectively, and the parent side of the EA at 12 months, $t(554)=-2.31, p<0.05$.

We then examined the associations between background characteristics (educational level, relationship status, whether the baby was planned for) and the study variables (relationship satisfaction, PRF, EA and infant SEB, respectively) using Student's t-tests. For the purposes of these analyses, categorical variables (educational level, relationship status) were dichotomized to maintain adequate cell sizes (lower/high educational level, married/cohabiting parent). The number of single parents was very low $(N=11)$. After checking that there were no statistical differences between the three groups (married, cohabiting, single) in relation to other background or study variables, they were dropped from the analyses to keep the group sizes equal. The results indicate associations for higher educational level and appropriateness of reasoning for mothers and both PRF dimensions for fathers (Table 3). Additionally, among mothers, higher educational level was associated with higher EA and relationship satisfaction at 12 months. Being married (vs. cohabiting) was associated systematically to higher relationship satisfaction at three and 12 months for both mothers and fathers, and higher interest and curiosity and appropriateness of reasoning for mothers at three months.
Significant small to large size correlations (Tables 4 and 5) were found between the study variables for both mothers' and fathers' scores revealing that the scores between the study variables covary. Most systematic associations across different ages were found between low level of relationship satisfaction and low level of interest and curiosity and appropriateness of reasoning for both mothers and fathers, correlations ranging between $r=-0.14$ and -0.19 in mothers and $r=-0.23$ and -0.43 in fathers (correlations being negative as higher scores in relationship satisfaction measure indicate lower levels of satisfaction and higher scores in PRF dimensions indicate higher parental reflectiveness). Furthermore, low relationship satisfaction correlated with low EA, correlations ranging between $r=-0.32$ and -0.36 for mothers and between $r=-0.26$ and -0.45 for fathers (correlations being negative as higher scores in relationship satisfaction measure indicate lower levels of satisfaction and higher scores in EA dimensions indicate higher emotional availability). EA correlated also with PRF, correlations ranging between $r=0.04-0.27$ for mothers and $r=0.04-0.28$ for fathers. Infant SEB variables also correlated with both relationship satisfaction and PRF, correlations ranging between $r=0.01$ and -0.48 for mothers and 0.09 and -0.35 for fathers (correlations being positive between high levels of EA, PRF and infant social competence while negative with infant problem behavior, and the reverse for correlations between low relationship satisfaction and social competence and infant problem behavior).

\section{Path Analysis}

Model coefficients for mothers are summarized in Fig. 2 and for fathers in Fig. 3.

\section{Stability}

For both mothers and fathers, relationship satisfaction at 12 months was significantly predicted by relationship satisfaction at three months, while PRF at 12 months was significantly predicted by PRF at three months.

\section{Direct effects}

For mothers, high relationship satisfaction at 12 months and high PRF at 12 months significantly predicted high EA. Lower levels of infant problem behaviors were significantly predicted only by high levels of PRF at 12 months, while social competence was significantly predicted by none of the variables. Also, relationship satisfaction at three months and PRF at three months had no significant direct effects on the dependent variables. 
Table 2 Means and standard deviations of the study variables for mothers and fathers

\begin{tabular}{|c|c|c|c|c|c|c|c|c|}
\hline \multirow[t]{3}{*}{ Variables } & \multicolumn{4}{|c|}{ Postpartum 3 months } & \multicolumn{4}{|c|}{ Postpartum 12 months } \\
\hline & \multicolumn{2}{|c|}{ Mothers } & \multicolumn{2}{|c|}{ Fathers } & \multicolumn{2}{|c|}{ Mothers } & \multicolumn{2}{|c|}{ Fathers } \\
\hline & $M$ & $S D$ & $M$ & $S D$ & $M$ & $S D$ & $M$ & $S D$ \\
\hline Index of Marital Satisfaction & 12.96 & 11.34 & 12.83 & 12.23 & 16.33 & 14.1 & 15.44 & 14.43 \\
\hline \multicolumn{9}{|l|}{ Parental reflective functioning } \\
\hline Interest and curiosity & 6.16 & 0.77 & 5.88 & 0.92 & 6.07 & 0.78 & 5.87 & 0.85 \\
\hline Appropriateness & 6.16 & 0.90 & 5.78 & 0.99 & 6.14 & 0.87 & 5.84 & 1.00 \\
\hline \multicolumn{9}{|l|}{ Emotional availability } \\
\hline Parental emotional availability & & & & & 13.48 & 3.09 & 14.18 & 2.71 \\
\hline Dyadic emotional availability & & & & & 22.45 & 3.05 & 22.92 & 2.74 \\
\hline \multicolumn{9}{|l|}{ Infant SEB } \\
\hline BITSEA problem scale & & & & & 9.30 & 4.89 & 9.65 & 5.66 \\
\hline BITSEA competence scale & & & & & 15.73 & 2.93 & 15.73 & 2.93 \\
\hline
\end{tabular}

Table 3 Associations between the background and study variables for mothers and fathers

\begin{tabular}{|c|c|c|c|c|c|c|c|c|c|c|c|c|}
\hline \multirow[t]{3}{*}{ Background and study variables } & \multicolumn{4}{|c|}{ Educational level (High/Low $)^{a}$} & \multicolumn{4}{|c|}{ Marital status (Married/Cohabiting) } & \multicolumn{4}{|c|}{ Pregnancy planned for } \\
\hline & \multicolumn{2}{|c|}{ Mothers } & \multicolumn{2}{|l|}{ Fathers } & \multicolumn{2}{|c|}{ Mothers } & \multicolumn{2}{|l|}{ Fathers } & \multicolumn{2}{|c|}{ Mothers } & \multicolumn{2}{|l|}{ Fathers } \\
\hline & $t(427)$ & $p$ & $t(125)$ & $p$ & $t(427)$ & $p$ & $t(125)$ & $p$ & $t(407)$ & $p$ & $t(119)$ & $p$ \\
\hline Relationship satisfaction at 3 months & 1.56 & 0.12 & -0.26 & 0.79 & 2.98 & 0.01 & 1.99 & 0.04 & -1.11 & 0.43 & -2.71 & 0.05 \\
\hline Relationship satisfaction at 12 months & 2.81 & 0.01 & -1.36 & 0.17 & 2.85 & 0.01 & 2.08 & 0.03 & -0.46 & 0.66 & -1.07 & 0.28 \\
\hline \multicolumn{13}{|l|}{ Parental reflective functioning } \\
\hline Interest and curiosity at 3 months & -0.85 & 0.34 & -2.16 & 0.03 & -2.57 & 0.01 & -1.55 & 0.12 & 0.18 & 0.85 & -0.99 & 0.32 \\
\hline Appropriateness of reasoning at 3 months & -1.69 & 0.05 & -1.18 & 0.07 & -2.21 & 0.03 & -1.39 & 0.16 & 1.56 & 0.11 & 0.89 & 0.37 \\
\hline Interest and curiosity at 12 months & 0.63 & 0.53 & -2.28 & 0.02 & -1.35 & 0.17 & -0.86 & 0.39 & 0.80 & 0.42 & 0.87 & 0.35 \\
\hline Appropriateness of reasoning at 12 months & -1.67 & 0.05 & -2.59 & 0.01 & -0.16 & 0.87 & -1.47 & 0.14 & -0.18 & 0.87 & -0.15 & 0.87 \\
\hline \multicolumn{13}{|l|}{ Emotional availability 12 months } \\
\hline Parent EA & -1.31 & 0.19 & -0.18 & 0.85 & -0.75 & 0.45 & -1.05 & 0.29 & 0.31 & 0.75 & -0.73 & 0.46 \\
\hline Dyadic EA & -2.53 & 0.05 & 0.52 & 0.59 & -0.26 & 79 & -0.20 & 0.89 & 0.32 & 0.06 & 0.24 & 0.11 \\
\hline \multicolumn{13}{|l|}{ Infant SEB 12 months } \\
\hline Problem behavior & 0.71 & 0.42 & 1.24 & 0.21 & 0.08 & 0.93 & 0.35 & 0.72 & -0.10 & 0.94 & 0.53 & 0.59 \\
\hline Social competence & 0.78 & 0.07 & -0.20 & 0.84 & -0.26 & 0.79 & -1.54 & -12 & 0.70 & 0.48 & 1.63 & 0.11 \\
\hline
\end{tabular}

${ }^{a}$ Educational Level High $=$ Polytechnic and academic degree, Educational Level Low $=$ Compulsory school and professional/high school

For fathers, none of the variables predicted EA. Lower level of problem behaviors were significantly predicted only by high PRF at 12 months, while higher infant social competence was significantly predicted only by higher relationship satisfaction at 12 months. In addition, relationship satisfaction and PRF at three months had no significant direct effects on the dependent variables.

\section{Spillover model}

For mothers, low relationship satisfaction at three months had a significant indirect effect on low EA both trough low relationship satisfaction at 12 months, $\beta=-0.19,95 \%$ CI $[-0.29,-0.11]$ and through low PRF at 12 months, $\beta=-0.02,95 \%$ CI $[-0.04,-0.003]$. Higher PRF at three months had a significant indirect effect on higher EA trough higher PRF at 12 months, $\beta=0.12,95 \%$ CI [0.03, 0.21]. The indirect effect of high PRF at three months on lower level of reported infant problem behaviors was significant trough high PRF at 12 months, $\beta=-0.17,95 \% \mathrm{CI}$ $[-0.26,-0.08]$ but not trough relationship satisfaction at 12 months, $\beta=-0.01,95 \%$ CI $[-0.04,0.00]$. The indirect effect of lower relationship satisfaction at three months on higher infant problem behaviors was significant trough lower PRF at 12 months, $\beta=0.02,95 \%$ CI [0.01, 0.05] but not trough relationship satisfaction at 12 months, $\beta=0.10$, 95\% CI [ $-0.01,0.23]$. Additionally, no indirect effects were significant in predicting social competence. 
Table 4 Correlations between study variables for mothers $(n=429)$

\begin{tabular}{|c|c|c|c|c|c|c|c|c|c|}
\hline & 1 & 2 & 3 & 4 & 5 & 6 & 7 & 8 & 9 \\
\hline \multicolumn{10}{|c|}{ Index of Marital Satisfaction } \\
\hline 1. 3 months & - & & & & & & & & \\
\hline 2. 12 months & $0.71 * *$ & - & & & & & & & \\
\hline \multicolumn{10}{|c|}{ PRFQ-Fi 3 months } \\
\hline 3. Interest & $-0.16^{* *}$ & $-0.14 * *$ & - & & & & & & \\
\hline $\begin{array}{l}4 . \\
\text { Appropriatenes }\end{array}$ & $-0.15^{* *}$ & $-0.18 * *$ & $0.58 * *$ & - & & & & & \\
\hline \multicolumn{10}{|c|}{ PRFQ-Fi 12 months } \\
\hline 5. Interest & $-0.15^{*}$ & $-0.15^{* *}$ & $0.68 * *$ & $0.27 * *$ & & & & & \\
\hline $\begin{array}{l}6 . \\
\text { Appropriatenes }\end{array}$ & $-0.19 * *$ & $-0.18^{*}$ & $0.19 *$ & $0.61 * *$ & & & & & \\
\hline \multicolumn{10}{|l|}{ EA 12 months } \\
\hline 7. Parent EA & $-0.32 * *$ & $-0.36 * *$ & 0.04 & $0.22 * *$ & 0.02 & $0.26 * *$ & & & \\
\hline $\begin{array}{l}8 . \\
\text { Dyadic EA } 12\end{array}$ & $-0.32 * *$ & $-0.36^{* *}$ & $0.21 * *$ & $0.27 * *$ & $0.24 * *$ & $0.34 * *$ & $0.64 * *$ & & \\
\hline \multicolumn{10}{|c|}{ BITSEA 12 months } \\
\hline $\begin{array}{l}\text { 9. BITSEA } \\
\text { problem }\end{array}$ & $0.23 * *$ & $0.24 * *$ & 0.04 & $-0.11^{*}$ & $-0.14^{*}$ & $-0.20 *$ & $-0.33 * *$ & $-0.48 * *$ & - \\
\hline $\begin{array}{l}\text { 10. BITSEA } \\
\text { competence }\end{array}$ & $-0.13 *$ & $-0.11^{*}$ & $0.22 * *$ & $0.10^{*}$ & $0.23 * *$ & 0.11 & 0.01 & $0.26 * *$ & $-0.16^{* *}$ \\
\hline
\end{tabular}

${ }^{*} p<0.05 ; * * p<0.01 ; * * * p<0.001$

Table 5 Correlations between study variables for fathers $(n=127)$

\begin{tabular}{|c|c|c|c|c|c|c|c|c|c|}
\hline & 1 & 2 & 3 & 4 & 5 & 6 & 7 & 8 & 9 \\
\hline \multicolumn{10}{|c|}{ Index of Marital Satisfaction } \\
\hline 1. 3 months & - & & & & & & & & \\
\hline 2. 12 months & $0.75 * *$ & - & & & & & & & \\
\hline \multicolumn{10}{|c|}{ PRFQ-Fi 3 months } \\
\hline 3. Interest & $-0.41 * *$ & $-0.34 * *$ & - & & & & & & \\
\hline $\begin{array}{l}4 . \\
\text { Appropriateness }\end{array}$ & $-0.32 * *$ & $-0.33^{* *}$ & $0.53 * * *$ & - & & & & & \\
\hline \multicolumn{10}{|c|}{ PRFQ-Fi 12 months } \\
\hline 5. Interest & $-0.32 *$ & $-0.23 * *$ & $0.68 * *$ & $0.42 * *$ & - & & & & \\
\hline $\begin{array}{l}6 . \\
\text { Appropriateness }\end{array}$ & $-0.33 * *$ & $-0.33 * *$ & $0.45^{* *}$ & 0.58 & $0.61 * *$ & - & & & \\
\hline \multicolumn{10}{|l|}{ EA 12 months } \\
\hline 7. Parent EA & $-0.26 * *$ & $-0.31 * *$ & 0.04 & $0.21 *$ & 0.13 & $0.23 * *$ & - & & \\
\hline 8. Dyadic EA & $-0.45 * *$ & $-0.37 * *$ & $0.21 * *$ & $0.28 *$ & $0.25 * *$ & $0.20 * *$ & $0.72 * *$ & & \\
\hline \multicolumn{10}{|c|}{ BITSEA 12 months } \\
\hline $\begin{array}{l}\text { 9. BITSEA } \\
\text { problem }\end{array}$ & $0.23 * *$ & $0.29 * *$ & $-0.19 *$ & $-0.19^{*}$ & $-0.13^{*}$ & $-0.35^{*}$ & $-0.32 * *$ & $-0.33 * *$ & \\
\hline $\begin{array}{l}\text { 10. BITSEA } \\
\text { competence }\end{array}$ & $-0.19 *$ & $-0.30 * *$ & $0.32 * *$ & $0.22 *$ & $0.22 * *$ & $0.25^{*}$ & 0.09 & $0.33 * *$ & $-0.23^{*}$ \\
\hline
\end{tabular}

$* p<0.05 ; * * p<0.01 ; * * * p<0.001$

For fathers, low relationship satisfaction at three months had a significant indirect effect on lower level of reported infant social competence trough low relationship satisfaction at 12 months, $\beta=-0.21,95 \%$ CI $[-0.44$, -0.01]. High PRF at three months had significant indirect effect on lower level of reported infant problem behavior 
Fig. 2 Results of the path analysis for mothers. Note. The figure show standardized coefficients. Direct effects of the independent variables on the dependent variables are not shown in the figure for the sake of clarity

Fig. 3 Results of the path analysis for fathers. Note. The figure show standardized coefficients. Direct effects of the independent variables on the dependent variables are not shown in the figure for the sake of clarity
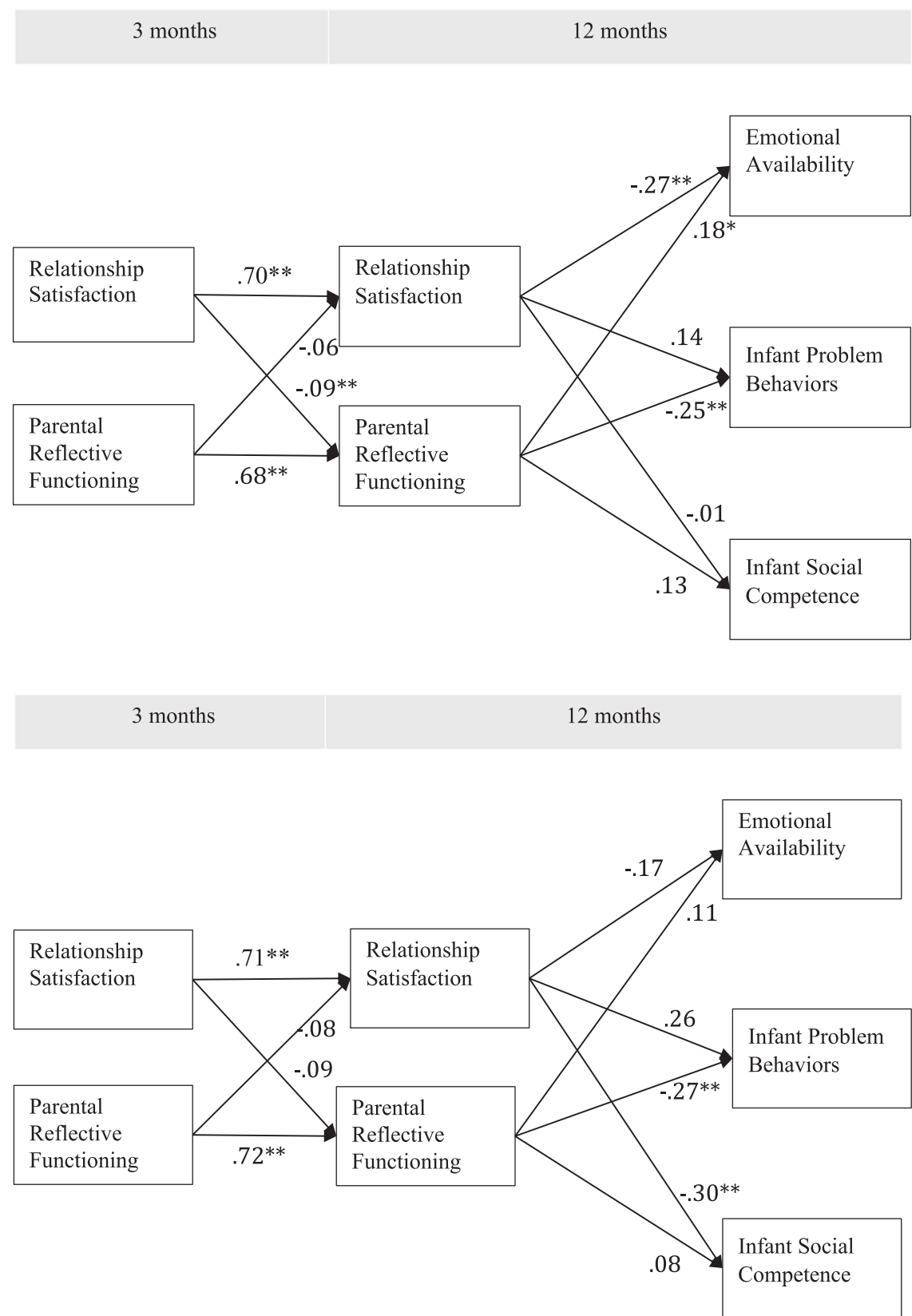

trough high PRF at 12 months, $\beta=-0.20,95 \%$ CI $[-0.37,-0.04]$. The other indirect effects were not statistically significant.

We also tested a separate model for mothers including the covariates of relationship status (married/cohabiting), educational status and whether the baby was planned or not. The results show that relationship status predicted significantly PRF $(\beta=0.14, p<0.01)$ and relationship satisfaction $(\beta=-0.13, p<0.01)$, at three months, while educational status predicted significantly relationship satisfaction $(\beta=-0.08, p<0.05)$, and infant problem behaviors $(\beta=-0.13, p<0.01)$ at 12 months. All the paths that were significant in the model without covariates remained significant. In addition, in the model with covariates, the paths from relationship satisfaction to problem behaviors and from PRF to infant social competence at 12 months, respectively, became significant $(\beta=0.17, p<0.05 ; \beta=0.15, p<0.05)$. For the sake of clarity, these results are not presented here. Results are available from the first author upon request.

\section{Discussion}

The main aim was to show how relationship satisfaction and PRF predict parent-child EA and infant SEB from three to 
twelve months measured among first-time Finnish parents. Mothers and fathers were studied separately. The main results support the hypothesis that both relationship satisfaction and PRF were highly stable, interrelated with each other and they both showed direct effects on parent-child EA and infant SEB for both mothers and fathers. The results also supported a meditational model between relationship satisfaction, PRF and relational and child related outcomes for the mothers but not for the fathers.

The main findings showed, firstly, that both relationship satisfaction and PRF were highly stable for both mothers and fathers across the follow-up period. The results regarding stability of relationship satisfaction is consistent with previous follow-up studies during infancy (Doss and Rhoades 2017; Twenge et al. 2003) while the stability of PRF has been studied less thus far. Second, relationship satisfaction was related to the PRF for both mothers and fathers at three and 12 months. This result supports previous findings on their interrelations (e.g., Luyten et al. 2017). The results of the path analysis further showed that both relationship satisfaction and PRF at 12 months had direct effects on EA and infant SEB also measured at 12 months but that the results were also different for mothers and fathers. These results are generally supported by previous findings indicating that both low relationship satisfaction and low PRF are risk factors for both later parent-child relationship problems (Luyten et al. 2017; Rostaker and Whitaker 2016), and child social-emotional skills or behavioral problems (Camoirano 2017; Heinrichs et al. 2010). However, they also indicate the significance of studying mothers and fathers separately, as has also been highlighted previously (Lawerence et al. 2008; Camoirano 2017).

Looking first at the mean levels of predictor study variables between mothers and fathers, the results indicated no differences between mothers and fathers level of relationship satisfaction, contrasting some previous findings indicating more dissatisfaction for mothers (Twenge et al. 2003). In turn, the mean levels for PRF dimensions of interest and wondering about the mental states and appropriateness of reasoning were higher for mothers than for fathers at the age of three but not at 12 months. This result is in line with findings by Pajulo et al. (2018), assessing parental reflectiveness when the babies were six months, as well as with a study of older children by Pazzagli et al. (2018). In the present study, the result may reflect the fact that mothers stay at home taking care of the infant and gain more experience and knowledge in interpreting their behaviors in a mentalizing way. As this difference was no longer apparent at 12 months also suggests that by then, fathers may also have gained enough experience in taking care of and getting to know their baby. However, this result is not in line with findings by Luyten et al. (2017) where the mother's PRFQ scores were still higher at 12 months, as well as with Pazzagli et al. (2018) who found significant differences among schoolaged children, indicating the need to study mothers and fathers separately in the future studies.

As far as the predictive relations between the study variables were concerned, for the mothers, the path analysis results supported our hypothesis for direct predictive effects from relationship satisfaction to higher EA, and from higher PRF to higher EA and lower infant problem behaviors. In addition, supporting our third hypothesis, there was also support for the spillover hypothesis where a mediated effect from earlier higher relationship satisfaction to higher EA and lower infant problem behavior was found via current level of PRF. The mediated effects result for mothers is in line with Jessee et al. (2018) finding that RF was associated with higher relationship satisfaction and co-parenting among mothers but not fathers. However, in their study, the order of causality was from earlier (prenatal) RF to later relationship satisfaction as they examined RF measured from the AAI, which may reflect more general capability of mentalizing thought to underlie better skills in couples relations too as discussed by Jessee et al. (2018). The present results for mothers seem to indicate the opposite order of causality with regards to PRF, supporting the growing literature that indicates spillover from relationship functioning to parenting skills (Christopher et al. 2015), and previous similar findings on the associations between PRFQ and EA (Luyten et al. 2017). A contagion or a spillover process seems to occur such that the higher satisfaction experienced in the relationship is transmitted into better PRF skills, which, in turn, affect the perceived EA and lower level of perceived infant problem behaviors. It may be that for mothers taking care of their young babies at home, the positive experiences of relationship satisfaction may act as a buffer against stress and help them to maintain an insightful and curious stance towards their infant's mental states. In turn, PRF seems to help mothers to navigate in their new role as parents as it predicted higher EA and lower perceived infant problem behaviors. The experience of feeling supported, loved and happy in the current relationship may be especially relevant in the transition to parenthood, which puts pressure on the emotional regulation strategies for most new parents. Security in relationship attachment is considered to be the key source of adult emotional regulation (Mikulincer and Shaver 2005). The capability of being able to deal with everyday stress and regulate emotions, in turn, paves the way into the PRF skill of being able to stay curious and wondering what the baby needs and is signaling.

For fathers, however, such mediated effects were not found. The path analysis supported the direct effects model, in which higher relationship satisfaction predicted higher perceived infant social competency, and higher PRF lower 
infant problem behaviors while no paths to EA became statistically significant. Our PRF results are similar to previous studies among fathers indicating that the father's RF is related specifically to the social-emotional development of their children (Sharp and Fonagy 2008). Furthermore, the results regarding the absence of direct or mediated effects from relationship satisfaction to EA, which is a relational construct assessing emotional availability with the child, are supported by previous findings where father's experience of relationship satisfaction was not related to interaction within a family (Korja et al. 2016), but was related to lower child well-being (e.g., Knopp et al. 2017). In considering the differences found between mothers and fathers, the fact that more mothers than fathers participated needs to be taken into account. It may reflect demographic sampling differences, which may, in turn, influence the direct and indirect effects that were found between the study variables. However, the mothers and fathers didn't differ in terms of any of the background variables, suggesting also that the differences found in the associations may be found in other samples too.

In the study of relationship satisfaction as well as PRF taking into account various contextual factors has been considered to be important (Mortensen et al. 2012; Pajulo et al. 2006; Rosenblum et al. 2008) which was also evident from our results. Firstly, the mean levels of relationship satisfaction were not beyond any clinical cut-off points (see Torkan and Moulavi 2009). This may reflect the fact that our present sample is a community-based convenience sample and represents sociodemographically a more advantaged group at least it terms of higher education level. This supports the previous findings that there are many moderators, including the SES, which may influence the drop in relationship satisfaction during the transition to parenthood (Doss and Rhoades 2017). This was also evident here for mothers at 12 months, when a higher level of education was significantly related to higher relationship satisfaction. Additionally, from the other background factors, the most systematic associations were between being married (as opposed to cohabiting) and relationship satisfaction for both mothers and fathers. This supports previous findings on a negative cohabitation effect on relationship satisfaction that prevailed after controlling for various covariates (Mortensen et al. 2012). With regard to the PRF, the dimension of appropriateness of reasoning was most systematically significantly related to higher education level for both mothers and fathers and being married for mothers. This is in line with results from a larger sample of Finnish parents (Pajulo et al. 2018) as well as with Luyten et al. (2017), whose findings that pre-mentalizing features were especially related with lower level of education. That is, their result was the opposite of appropriateness of reasoning, malevolent attributions, and inability to enter into the subjective world of the child. For mothers, being married also seemed to protect the appropriateness of reasoning in early infancy, at three months. Perhaps being married gives more felt sense of security for mothers during the emotionally vulnerable times of building a new relationship with the first-born child. Finally, in contrast to some previous findings from a clinical sample (Pajulo et al. 2006), whether the baby was planned or not was not related to the study's variables, possibly reflecting also the low number of unplanned pregnancies in this high SES sample. Together, results suggest that individuals who are socioeconomically or socially more advantaged may also suffer less from problems in social learning and thus mentalizing (Fonagy et al. 2015).

The limitations of the present study are, firstly, the use of self-reports for assessment of all the study variables. Thus, the findings in this study may in part reflect shared method variance. The high correlations between independent variables in the path models also make estimation vulnerable to multicollinearity, leading to an increase in the possibility of Type II error, meaning that we don't get a significant relationship in places where we should have one. Furthermore, using questionnaires such as the PRFQ-Fi and EAself report can never give clinically as rich, detailed and idiosyncratic information as we can get using interviewbased measures such as the PDI-RF (Slade et al. 2005) or observation of EA (Biringen 2008) from videotapes.

Additionally, in our study, we focused only on two dimensions of parental reflectiveness as measured by the PRFQ-Fi: interest and wondering about the mental states and appropriateness of reasoning (making accurate assumptions about mental states underneath behavior). The original version of the PRFQ-Fi (Pajulo et al. 2018) contains dimensions measuring understanding opacity of the minds and uncertainty of mental states. These were dropped in the present study due to the low internal consistency of the scales, and the fact that they were not correlated with other dimensions of PRFQ-Fi. Also, for similar reasons one dimension of the original EA self-report, namely child emotional availability, was dropped. Some of the problems regarding internal consistencies in these measures have also been encountered in previous studies (e.g., Pajulo et al. 2018; Luyten et al. 2017). More studies examining the reliability and validity of these measures is therefore needed.

Furthermore, although questionnaires in general are useful in studies with large samples, the present results should nevertheless, be replicated using also interviewand observation-based tools. In clinical use, the combination of questionnaires (screening purposes) and more detailed methods for deeper understanding is recommended, in order to yield a richer and more objective base for planning interventions. 
Finally, our sample represented socioeconomically advantaged parents in terms of education and relationship status. Replication of the findings with more representative cohort samples as well as clinically more vulnerable samples is needed. More mothers than fathers participated, which may reflect the fact that it is still most often mothers who take their children to well-baby clinics, where the data collection and recruitment for the study was done. This may result in sampling bias and in future studies, particular attention in recruiting fathers is essential. Nevertheless, the mothers and fathers in the present study did not differ from each other in relation to any of the background variables. Finally, in future studies examining the interrelations of the study variables among family units where both parents have answered the questionnaires is of special relevance. It is to be expected that both relationship satisfaction and PRF might have an impact on the spouse causing potential positive (or negative) cycles of interaction.

Nonetheless, the longitudinal findings on meaningful relations between relationship satisfaction and PRF, including here interest and curiosity and appropriateness of reasoning, and their predictive relations with EA and/or indicators of infant SEB, support the previous empirical findings and general family systems theoretical propositions. Also, our results show that acknowledging various contextual factors related to family well-being, such as the SES and marital status, is important as they were also significantly related to study variables in the present study. As such, clinically, supporting parents with their first-born babies in terms of relationship relations may also be significant when trying to strengthen their newly developing parental skills, here reflectiveness, especially with lower SES and co-habiting (as opposed to married) status. Future studies including both mothers and fathers with more clinical samples and using diverse measures for assessing PRF is needed.

Acknowledgements This study was funded by the Signe and Ane Gyllenberg Foundation and Folkhälsan Research Institute

Funding Open access funding provided by University of Helsinki including Helsinki University Central Hospital.

\section{Compliance with Ethical Standards}

Conflict of Interest The authors declare no competing interests.

Ethical Approval We assert that all procedures contributing to this work comply with the ethical standards of the relevant national and institutional guidelines on human experimentation and with the Helsinki Declaration of 1975, as revised in 2008. All the participants received written information of their rights of voluntary participation, and their right to refuse to participate without any interference to their treatment as usual. They gave written agreements for their participation.
Publisher's note Springer Nature remains neutral with regard to jurisdictional claims in published maps and institutional affiliations.

Open Access This article is licensed under a Creative Commons Attribution 4.0 International License, which permits use, sharing, adaptation, distribution and reproduction in any medium or format, as long as you give appropriate credit to the original author(s) and the source, provide a link to the Creative Commons license, and indicate if changes were made. The images or other third party material in this article are included in the article's Creative Commons license, unless indicated otherwise in a credit line to the material. If material is not included in the article's Creative Commons license and your intended use is not permitted by statutory regulation or exceeds the permitted use, you will need to obtain permission directly from the copyright holder. To view a copy of this license, visit http://creativecommons. org/licenses/by/4.0/.

\section{References}

Biringen, Z. (2008). Emotional Availability (EA) scales manual, 4th edition. Part 1: Infancy/Early Childhood version (child aged 0-5 years). Boulder.

Biringen, Z., Derscheid, D., Vliegen, N., Closson, L., \& Easterbrooks, M. A. (2014). Emotional availability (EA): theoretical background, empirical research using the EA Scales, and clinical applications. Developmental Review, 34(2), 114-167. https://doi. org/10.1016/j.dr.2014.01.002.

Briggs-Gowan, M. J., Carter, A. S., Irwin, J. R., Wachtel, K., \& Cicchetti, D. V. (2002). Brief Infant-Toddler Social and Emotional Assessment (BITSEA) manual, version 2.0. New Haven, CT: Yale University.

Camoirano, A. (2017). Mentalizing makes parenting work: A review about parental reflective functioning and clinical interventions to improve it. Frontiers in Psychology, 8. https://doi.org/10.3389/ fpsyg.2017.00014

Christopher, C., Umemura, T., Mann, T., Jacobvitz, D., \& Hazen, N. (2015). Marital quality over the transition to parenthood as a predictor of coparenting. Journal of Child and Family Studies, 24 (12), 3636-3651. https://doi.org/10.1007/s10826-015-0172-0.

Cowan, P.A., Cowan, C.P. (2012). Normative family transitions, couple relationship quality, and healthy child development. In Walsh, F. (Ed). Normal family processes: growing diversity and complexity (pp. 428-451). Guilford Press.

Davies, P. T., Sturge-Apple, M. L., Woitach, M. J., \& Cummings, E. M. (2009). A process analysis of the transmission of distress from interparental conflict to parenting: adult relationship security as an explanatory mechanism. Developmental Psychology, 45(6), 1761-1773. https://doi.org/10.1037/a0016426.

Don, B. P., \& Mickelson, K. D. (2014). Relationship satisfaction trajectories across the transition to parenthood among low-risk parents: relationship satisfaction trajectories. Journal of Marriage and Family, 76(3), 677-692. https://doi.org/10.1111/jomf.12111.

Doss, B. D., \& Rhoades, G. K. (2017). The transition to parenthood: impact on couples' romantic relationships. Current Opinion in Psychology, 13, 25-28. https://doi.org/10.1016/j.copsyc.2016. 04.003.

Doss, B. D., Rhoades, G. K., Stanley, S. M., \& Markman, H. J. (2009). The effect of the transition to parenthood on relationship quality: an 8-year prospective study. Journal of Personality and Social Psychology, 96(3), 601-619. https://doi.org/10.1037/a0013969.

Fonagy, P., Gergely, G., Jurist, E., \& Target, M. (2002). Mentalization, affective regulation and the development of the self. New York, NY: Basic Books. 
Fonagy, P., Luyten, P., \& Allison, E. (2015). Epistemic petrification and the restoration of epistemic trust: a new conceptualization of borderline personality disorder and its psychosocial treatment. Journal of Personality Disorders, 29(5), 575-609. https://doi.org/ 10.1521/pedi.2015.29.5.575.

Galobardes, B., Shaw, M., Lawlor, D. A., Lynch, J. W., \& Smith, G. D. (2006). Indicators of socioeconomic position (part 1). Journal of Epidemiology \& Community Health, 60(1), 7-12. https://doi. org/10.1136/jech.2004.023531.

Haapsamo, H., Ebeling, H., Soini, H., Joskitt, L., Larinen, K., Penninkilampi-Kerola, V., Carter, A., \& Moilanen, I. (2009). Screening infants with social and emotional problems: a pilot study on the brief infant toddler social and emotional assessment (BITSEA) in northern Finland. International Journal of Circumpolar Health, 68(4), 386-393. https://doi.org/10.3402/ijch. v68i4.17365.

Hakulinen-Viitanen, T., \& Pelkonen, M. (2009). Lastenneuvola lapsen ja perheen terveyden ja hyvinvoinnin edistäjänä. In J. Lammi-Taskula, S. Karvonen Sakari \& S. Salme (Eds.), Lapsiperheiden hyvinvointi (pp. 152-161). Helsinki: THL.

Heinrichs, N., Cronrath, A.-L., Degen, M., \& Snyder, D. K. (2010). The link between child emotional and behavioral problems and couple functioning. Family Science, 1(3-4), 152-172. https://doi. org/10.1080/19424620.2010.569366.

Holmes, E. K., Sasaki, T., \& Hazen, N. L. (2013). Smooth versus rocky transitions to parenthood: family systems in developmental context: Smooth versus rocky transitions to parenthood. Family Relations, 62(5), 824-837. https://doi.org/10.1111/fare.12041.

Hudson, W. W. (1997). The WALMYR assessment scales scoring manual. Tallahassee, FL: WALMYR Publishing Company.

Jessee, A., Mangelsdorf, S. C., Wong, M. S., Schoppe-Sullivan, S. J., Shigeto, A., \& Brown, G. L. (2018). The role of reflective functioning in predicting marital and coparenting quality. Journal of Child and Family Studies, 27(1), 187-197. https://doi.org/10. 1007/s10826-017-0874-6.

Kalland, M., Fagerlund, Å., von Koskull, M., \& Pajulo, M. (2016). Families First: the development of a new mentalization-based group intervention for first-time parents to promote child development and family health. Primary Health Care Research \& Development, 17(1), 3-17. https://doi.org/10.1017/ S146342361500016X.

Kalland, M., Sinkkonen, J., Gissler, M., Meriläinen, J., \& Siimes, M. A. (2006). Maternal smoking behaviour, background and neonatal health in Finnish children subsequently placed in foster care. Child Abuse \& Neglect, 30(9), 1037-1047. https://doi.org/10. 1016/j.chiabu.2006.03.005.

Kaczynski, K. J., Lindahl, K. M., Malik, N. M., \& Laurenceau, J. P. (2006). Marital conflict, maternal and paternal parenting, and child adjustment: a test of mediation and moderation. Journal of Family Psychology, 20(2), 199 https://doi.org/10.1037/08933200.20.2.199.

Knopp, K., Rhoades, G. K., Allen, E. S., Parsons, A., Ritchie, L. L., Markman, H. J., \& Stanley, S. M. (2017). Within- and betweenfamily associations of marital functioning and child well-being: marital functioning and child well-being. Journal of Marriage and Family, 79(2), 451-461. https://doi.org/10.1111/jomf.12373.

Korja, R., Piha, J., Otava, R., Lavanchy-scaiola, C., Ahlqvist-Björkroth, S., Aromaa, M., \& Räihä, H., STEPS-study. (2016). Mother's marital satisfaction associated with the quality of mother-father-child triadic interaction. Scandinavian Journal of Psychology, 57(4), 305-312. https://doi.org/10.1111/sjop.12294.

Kouros, C. D., Papp, L. M., Goeke-Morey, M. C., \& Cummings, E. M. (2014). Spillover between marital quality and parent-child relationship quality: parental depressive symptoms as moderators. Journal of Family Psychology, 28(3), 315-325. https://doi.org/ 10.1037/a0036804.
Lawrence, E., Rothman, A. D., Cobb, R. J., Rothman, M. T., \& Bradbury, T. N. (2008). Marital satisfaction across the transition to parenthood. Journal of Family Psychology, 22(1), 41-50. https://doi.org/10.1037/0893-3200.22.1.41.

Lindblom, J., Vänskä, M., Flykt, M., Tolvanen, A., Tiitinen, A., Tulppala, M., \& Punamäki, R.-L. (2017). From early family systems to internalizing symptoms: the role of emotion regulation and peer relations. Journal of Family Psychology, 31(3), 316-326. https://doi.org/10.1037/fam0000260.

Luyten, P., \& Fonagy, P. (2015). The neurobiology of mentalizing. Personality Disorders: Theory, Research, and Treatment, 6(4), 366-379. https://doi.org/10.1037/per0000117.

Luyten, P., Mayes, L. C., Nijssens, L., \& Fonagy, P. (2017). The parental reflective functioning questionnaire: development and preliminary validation. PLOS ONE, 12(5), e0176218 https://doi. org/10.1371/journal.pone.0176218.

Mikulincer, M., \& Shaver, P. R. (2005). Attachment theory and emotions in close relationships: exploring the attachment-related dynamics of emotional reactions to relational events. Personal Relationships, 12(2), 149-168. https://doi.org/10.1111/j.13504126.2005.00108.x.

Mortensen, Ø., Torsheim, T., Melkevik, O., \& Thuen, F. (2012). Adding a baby to the equation. Married and cohabiting women's relationship satisfaction in the transition to parenthood. Family Process, 51(1), 122-139. https://doi.org/10.1111/j.1545-5300. 2012.01384.x.

Muthén, L. K., \& Muthén, B. O. (1998-2017). Mplus user's guide. Eighth Edition Los Angeles, CA: Muthén \& Muthén.

Pazzagli, C., Delvecchio, E., Raspa, V., Mazzeschi, C., \& Luyten, P. (2018). The parental reflective functioning questionnaire in mothers and fathers of school-aged children. Journal of Child and Family Studies, 27(1), 80-90. https://doi.org/10.1007/s10826017-0856-8.

Pajulo, M., Helenius, H., \& Mayes, L. (2006). Prenatal views of baby and parenthood: association with sociodemographic and pregnancy factors. Infant Mental Health Journal, 27(3), 229-250. https://doi.org/10.1002/imhj.20090.

Pajulo, M., Pyykkönen, N., Kalland, M., Sinkkonen, J., Helenius, H., Punamäki, R.-L., \& Suchman, N. (2012). Substance-abusing mothers in residential treatment with their babies: importance of pre- and postnatal maternal reflective functioning. Infant Mental Health Journal, 33(1), 70-81. https://doi.org/10.1002/imhj. 20342.

Pajulo, M., Tolvanen, M., Pyykkönen, N., Karlsson, L., Mayes, L., \& Karlsson, H. (2018). Exploring parental mentalization in postnatal phase with a self-report questionnaire (PRFQ): factor structure, gender differences and association with sociodemographic factors. The Finn Brain Birth Cohort Study. Psychiatry Research, 262, 431-439. https://doi.org/10.1016/j. psychres.2017.09.020.

Panula, V., Junttila, N., Aromaa, M., Rautava, P., \& Räihä, H. (2020). Parental psychosocial well-being as a predictor of the social competence of a child. Journal of Child and Family Studies, 29 (11), 3004-3019. https://doi.org/10.1007/s10826-020-01790-6.

Rosenblum, K. L., McDonough, S. C., Sameroff, A. J., \& Muzik, M. (2008). Reflection in thought and action: maternal parenting reflectivity predicts mind-minded comments and interactive behavior. Infant Mental Health Journal, 29(4), 362-376. https:// doi.org/10.1002/imhj.20184.

Rostad, W. L., \& Whitaker, D. J. (2016). The association between reflective functioning and parent-child relationship quality. Journal of Child and Family Studies, 25(7), 2164-2177. https:// doi.org/10.1007/s10826-016-0388-7.

Rutherford, H. J. V., Goldberg, B., Luyten, P., Bridgett, D. J., \& Mayes, L. C. (2013). Parental reflective functioning is associated with tolerance of infant distress but not general distress: Evidence 
for a specific relationship using a simulated baby paradigm. Infant Behavior and Development, 36(4), 635-641. https://doi.org/10. 1016/j.infbeh.2013.06.008.

Salo, S. J., Flykt, M., Mäkelä, J., Biringen, Z., Kalland, M., Pajulo, M., \& Punamäki, R. L. (2019). The effectiveness of Nurture and Play: a mentalisation-based parenting group intervention for prenatally depressed mothers. Primary Health Care Research \& Development, 20, e157 https://doi.org/10.1017/S1463423619000914.

Sharp, C., \& Fonagy, P. (2008). The parent's capacity to treat the child as a psychological agent: constructs, measures and implications for developmental psychopathology. Social Development, 17(3), 737-754. https://doi.org/10.1111/j.1467-9507.2007.00457.x.

Sheikh, M. A., Abelsen, B., \& Olsen, J. A. (2017). Education and health and well-being: direct and indirect effects with multiple mediators and interactions with multiple imputed data in Stata. Journal of Epidemiology and Community Health, jech-2016208671. https://doi.org/10.1136/jech-2016-208671.

Slade, A. (2005). Parental reflective functioning: an introduction. Attachment \& Human Development, 7(3), 269-281. https://doi. org/10.1080/14616730500245906.

Slade, A., Bernbach, E., Grienenberger, J., Levy, D., \& Locker, A. (2005). Addendum to reflective functioning scoring manual for use with the parent development interview. City University of New York.

Slade, A., Cohen, L. J., Sadler, L. S. \& Miller, M. (2009). The psychology and psychopathology of pregnancy: Reorganization and transformation. In C. H. Zeanah (Ed.), Handbook of infant mental health. (p. 22-39). New York, NY: The Guilford Press.

Steele, M., Kaniuk, J., Hodges, J., Asquith, K., Hillman, S., \& Steele, H. (2008). Measuring mentalization across contexts: links between representations of childhood and representations of parenting in an adoption sample. In E. Jurist, A. Slade \& S. Bergner (Eds.), Mind to mind: Infant research, neuroscience, and psychoanalysis (pp. 115-38). New York, NY: Other Press.

Sturge-Apple, M. L., Davies, P. T., Boker, S. M., \& Cummings, E. M. (2004). Interparental discord and parenting: testing the moderating roles of child and parent gender. Parenting, 4(4), 361-380. https://doi.org/10.1207/s15327922par0404_7.

Suchman, N. E., DeCoste, C. L., McMahon, T. J., Dalton, R., Mayes, L. C., \& Borelli, J. (2017). Mothering from the inside out: results of a second randomized clinical trial testing a mentalization-based intervention for mothers in addiction treatment. Development and Psychopathology, 29(2), 617-636. https://doi.org/10.1017/ S0954579417000220.

Talala, K., Härkänen, T., Martelin, T., Karvonen, S., Mäki-Opas, T., Marderbacka, K., ... \& Koskinen, S. (2014). Time trends in educational disparities in health and well-being in the Finnish population from 2000 to 2011. Suomen Lääkärilehti, 69, 2185-2192.

Torkan, H., \& Moulavi, H. (2009). Psychometrical properties of the Index of Marital Satisfaction (IMS). Journal of Psychology, 13 (149), 3-19.

Twenge, J. M., Campbell, W. K., \& Foster, C. A. (2003). Parenthood and marital satisfaction: a meta-analytic review. Journal of Marriage and Family, 65(3), 574-583. https://doi.org/10.2307/ 3600024.

Vliegen, N., Luyten, P., \& Biringen, Z. (2009). A multimethod perspective on emotional availability in the postpartum period. Parenting, 9 (3-4), 228-243. https://doi.org/10.1080/15295190902844514.

Wong, K. (2016). A study of stability: maternal reflective functioning from pregnancy to seven months postpartum. Wayne State University Dissertations. 1493. https://digitalcommons.wayne.edu/ oa_dissertations/1493. 